Tesis. Año 13, 12(15), 2019, 185-200

\title{
Función de la música y la indumentaria como signos de la identidad andina en Diamantes y pedernales
}

\author{
Ynés V. Alcántara Silva \\ ynesud@gmail.com
}

\section{Resumen}

Las manifestaciones culturales del mundo andino tienen una importante expresión en la narrativa de José María Arguedas. En Diamantes y pedernales, la música actúa como un factor unificador y revitalizador de la cultura andina, para lo cual se articula con los principios de su cosmovisión. Es así que la música se realciona estréchamante con los seres de este universo. Así, los personajes, los instrumentos musicales, los rituales y las prácticas sociales y culturales comparten una interrelación e interinfluencia. Por otro lado, la indumentaria de la comunidad indígena distingue e identifica a los personajes de la novela y se asocia con determinados significados. Tanto la música con su función de revitalización del mundo andino y la indumentaria de los personajes contribuyen a afirmar la identidad de la comunidad indígena en esta novela.

Palabras clave: Arguedas, música andina, indumentaria andina, Diamantes y pedernales.

\section{Abstract}

The cultural manifestations of the Andean world have an important expression in the narrative of José María Arguedas. In the novel Diamantes y pedernales, the music acts as a unifying and revitalizing factor of the Andean culture, for which it is articulated with the principles of its cosmovision. From this point of view, the music is closely related to the different beings that constitute the Andean universe. Thus, the characters, musical instruments, rituals and the social and cultural practices share an interrelation and inter-influence. On the other hand, the clothing, made up of a series of garments or outfits typical of the indigenous community, distinguishes and identifies the characters in the novel and is associated with certain meanings. Both the music with its function of revitalization of the Andean world and the clothing of the characters contribute to affirm the identity of the indigenous community in the world represented in Diamantes y pedernales.

Key words: Arguedas, Andean music, Andean clothing, revitalization, Diamantes y pedernales. 


\section{Función de la música y la indumentaria como sigmos de la identidad andina en Diamantes $y$ pedernales}

\section{Introducción}

La narrativa de José María Arguedas revela, con mucha maestría, prácticas culturales, conocimientos ancestrales y principios de los pueblos del ande que rigen la vida del runa. Las novelas de Arguedas ponen de relieve, entre otros rasgos, la música, el canto y la danza como elementos integradores. Entre ellas, Diamantes y pedernales se halla estructurada a partir de la música, lo que se manifiesta en diferentes planos y aspectos de la novela. En ese orden de interrelaciones, de correspondencia, de reciprocidad, de tensiones y equilibrio, la música se presenta como un agente unificador y revitalizador de la cultura andina.

El carácter unificador de la música se manifiesta en dos dimensiones: primero, a través de su carácter integrador y unificador, que guarda relación con los principios de relacionalidad, correspondencia, complementariedad y reciprocidad; y segundo, como expresión de un signo de identidad. En tal sentido, nos abocamos a explicar dichos aspectos a partir de determinadas escenas de la novela, la función de los instrumentos y los géneros musicales, y la actuación y simbolismo de sus protagonistas. Igualmente, relacionada con la música, se halla el vestuario que caracteriza a los personajes, que no solamente corresponde a la usanza tradicional, sino que se asocia de manera especial con expresiones culturales y rituales que contribuyen a afirmar la identidad de la comunidad india en el mundo representado en Diamantes y pedernales.

\section{La música y la relacionalidad andina}

El principio que nos ayuda a identificar las bases de unificación del pensamiento andino es la relacionalidad. El cosmos andino está interconectado; en él, la totalidad y el equilibrio subsisten en función de la relación de los diversos entes y seres que lo conforman. En este vínculo de conexión e interrelación, existen mecanismos que lo conflictúan y armonizan y que sirven de canales comunicacionales que unifican a los entes o seres en un universo. En Diamantes y pe- 
dernales, este rol es asumido por la música, pues esta se convierte en el vehículo que relaciona a los seres en cada parte del macro y microcosmos representados en la novela. Sobre este punto, Cornejo Polar (1997) sostiene:

El poder de la música se interpreta en el orden específico de la música india y en relación necesaria con los atributos de este mundo. La música es así emanación de la cultura quechua y en tanto ésta se define por su inserción en una naturaleza viviente, concebida y experimentada en términos inequívocamente animista, la música deviene de un signo mayor y más legítimo de la totalidad indígena y no sólo de algunos de sus elementos y atributos. (p. 143)

La unificación y la integración se expresan a través del principio de la relacionalidad del mundo. De este modo, la música actúa en Diamantes y pedernales como un agente unificador de la totalidad cósmica, se muestra desde todas sus variantes y acompaña el hilo conductor del relato. Los hechos narrados y las acciones se desarrollan al compás de la música, los cantos, las fiestas y las danzas. En el universo arguediano, la música y el canto emanan de diversas fuentes: humana, natural e instrumental. Estas voces adquieren mayor significado cuando toman el valor de códigos que permiten la interrelación y comunicación entre los seres representados en la novela: "Mariano tocaba fuertemente los huaynos alegres de esas regiones. En las cuerdas de alambre, de las notas altas, se regocijaba repitiendo la melodía; con la otra mano arrancaba los bajos en lo alto del arpa" (1983, T. II, p. 12)1. Mariano se constituye como uno de los emisores de música humana por excelencia. Su don para interpretar el arpa y su capacidad para crear melodías son reconocidos por todos los habitantes del pueblo.

En Diamantes y pedernales se establecen relaciones más profundas entre los sonidos producidos por los seres humanos, por la música y por los que emanan de la naturaleza. Sobre este aspecto, Vicky Wolff en un estudio sobre Los ríos profundos afirma: "Al eliminarse las barreras jerárquicas en el esquema comunicativo los emisores y los destinatarios del mundo andino forman parte de un yo colectivo que, a través de la comunicación, produce la información colectiva necesaria para la supervivencia de la cultura" (1983, p. 196). De este modo, la voz del músico representa a su cultura y lo incorpora a una totalidad unificada y articulada.

Las cualidades sonoras de las voces que aparecen en Diamantes y pedernales pueden presentar diversos matices: dulce, como la voz de Irma; apaciguadora, sanadora o purificadora, como la voz de Mariano; poderosa y profunda, como la voz de las mujeres de los pueblos fruteros cuando cantan el harawi. Entre las voces femeninas colectivas, están las "bellas pasñas" que cantan el harawi de la despedida:

Cuando Antolín salía de viaje, toda la comunidad lo despedía, en un extremo del pueblo, junto a una piedra inmensa cargada de arbustos y 
de yerbas (...). La gran piedra se cubría de niños. Abrazaban a Antolín todos, sin estrecharlo mucho, poniéndole después las manos sobre los hombros, Luego partía. Mariano permanecía a la sombra de la gran piedra y escuchaba el coro de la despedida, el kacharpariy; solo, porque siendo un upa nadie se quedaba cerca de él. Las mujeres se cubrían medio rostro con las mantas, se reunían en un grupo cerrado, y así cantaban el harawi de la despedida. Los hombres y los niños, las viejas, todos permanecían en su sitio, callados. (...) Al anochecer, entre el canto de los pájaros, sin la presencia del sol que tanto se había infundido del silencio de la despedida, todo el ayllu regresaba a la aldea, a bailar en la plaza y más tarde en la choza de la familia de Antolín. (1983, T. II, p. 16)

Este pasaje nos permite presenciar el ritual de la despedida. Antolín sale de su pueblo para llevar la "legendaria fruta" de su comunidad a otros pueblos más lejanos. Este acto congrega a toda la comunidad. Podemos observar cómo los comuneros despiden a Antolín con el canto de las pasñas, su canto permite la unificación de los corazones, de la fuerza del espíritu, del ánimo vital de hombres, mujeres y niños que lo abrazan y lo tocan para revitalizar su fuerza. E1 ritual de la despedida se cierra al ritmo de la música y la danza en la plaza del pueblo. La comunidad se unifica en Antolín; ellos no lo acompañan físicamente en este viaje, pero su ánimo, su fuerza y el canto del harawi lo acompañarán en la tarea de cumplir con un objetivo colectivo.

El siguiente esquema que proponemos ofrece una clasificación de los emisores de música en la novela de Arguedas a partir de dos fuentes:

\section{Clasificación de los emisores de música humana e instrumental en Diamantes y pedernales}

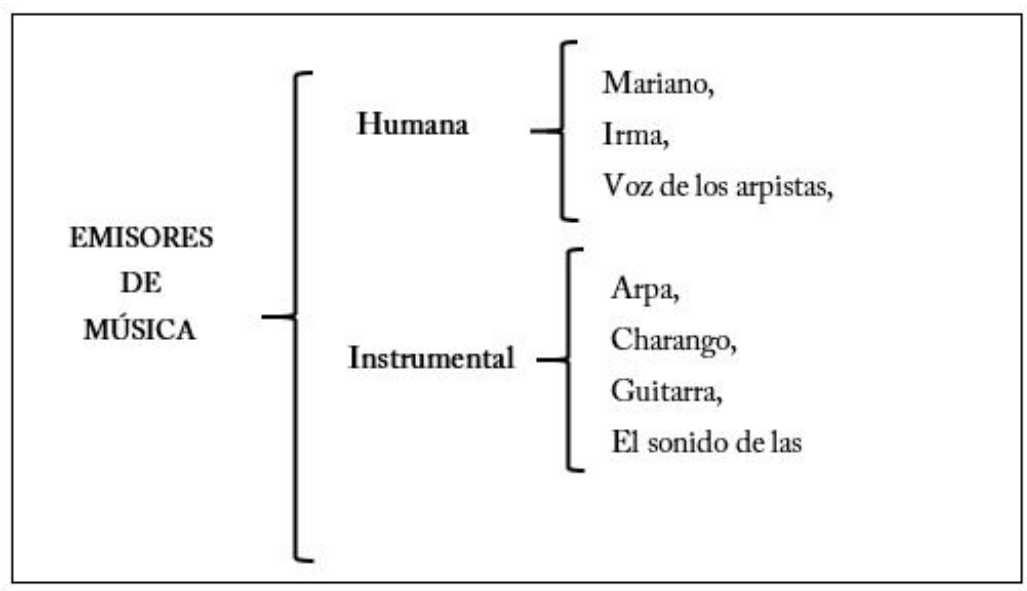

Fuente: Elaboración propia 
En el esquema, observamos dos tipos de emisores de música, humana e instrumental, que se relacionan y complementan (yanantin); el músico Mariano y su arpa se relacionan con esas fuentes de emisión. El arpista Mariano proviene de una familia de músicos; su padre y su abuelo fueron arpistas; su hermano, Antolín, ejecuta el charango. La voz femenina está representada en el personaje de Irma (la mestiza), cuyo canto es acompañado por la guitarra.

Los instrumentos musicales mestizos que aparecen en la novela son el arpa, el charango y la guitarra, que establecen grados de relacionalidad con sus intérpretes. A pesar de ser instrumentos foráneos, el indio ha logrado trasladar a ellos su alma, corazón y alegría, y ha incorporado, con mucha maestría, sus tonalidades en sus creaciones musicales y danzarías. El Upa Mariano ejecuta con maestría el arpa mestiza para componer tonalidades de su comunidad. De esta manera, el instrumento se complementa (yanantin) con el músico. En la oscuridad de la monturera, el arpista creaba las melodías que estaban inspiradas en su pueblo:

Don Mariano prendía el mechero, la callana de sebo con que solía alumbrase, y templaba su arpa. No tocaba las danzas y cantos que acababa de oír, sino los de su pueblo. Se agachaba hasta apoyar la frente en el gran arco del instrumento; y la música de los pueblos fruteros del “interior" nacía en ese cuarto oscuro. (1983, T. II, p. 13)

El arpa logra expresar el sentimiento del Upa Mariano; músico e instrumento se mimetizan para expresar las más hondas melodías. Los indios se identifican con el Upa arpista, su música se convierte en elemento de unificación con los lacayos de las diferentes haciendas de la puna. Mariano no habla con los mestizos, solo con los indios sirvientes, para quienes ejecuta sus melodías más íntimas. Esta idea está plasmada en el siguiente pasaje de la novela: "Los indios 'lacayos' lo buscaban en la monturera (...) Y algunos "lacayos" dormían en la monturera. Al amanecer, don Mariano tocaba el arpa, muy bajito, casi al oído de los indios" (1983, T. II, p. 35).

El arpa es un instrumento musical foráneo que el hombre del ande incorporó y adaptó a la forma y sonoridad musical de la música andina. Por ello, en el diseño de este instrumento, podemos observar que conviven sus principios. En su ejecución, hay un mayor contacto físico con el arpista y tiene lugar el encuentro (tinkuy), ya que, por sus características organológicas, este instrumento musical exige el encuentro entre la mano derecha (hanan) y la mano izquierda (burin) para su interpretación. La complementariedad se observa en las perforaciones de donde emanan las voces graves y agudas del arpa ${ }^{2}$. De este modo, se configura el yanantin en la ejecución del arpa: 
La posición de las perforaciones en la tapa armónica es de por sí complementaria: en los dos lados del instrumento, derecho hanan e izquierdo hurin, se encuentran perforaciones complementarias. Esta simetría es muy importante ya que, según los músicos andinos, las perforaciones sirven "para que salgan las voces". El plural utilizado hace referencia a por lo menos dos voces, grave y aguda, que podrían ser masculina y femenina. (Ferrier, 2012, p. 135)

Los instrumentos musicales de cuerda transitaron por procesos de transculturación, fueron adaptados e incorporados a la expresión artística y cultura andina. Para los músicos, el arpa es considerada la madre de la orquesta, asumida como instrumento femenino que suele estar acompañada por el violín ${ }^{3}$. Podemos ver que, en su interpretación, se expresa el sentir andino; a la vez, en su configuración, se expresa el principio de complementariedad (yanantin).

En Diamantes y pedernales, la guitarra acompaña a los huainos interpretados por Irma, la mestiza. En el siguiente pasaje de la novela, se muestra cómo la memoria vivifica las formas antiguas de interpretación de la guitarra: "Irma no aparecía en las calles del centro. Muy entrada la noche, o al mediodía, cantaba. La memoria le ayudó a reconstruir los temples de guitarra originales de su pueblo, de su lejana región nativa" (1983, T. II, p. 30). Los personajes a través de la interpretación musical se reencuentran con sus raíces, con su comunidad, con su familia (ayllu). Estos mantienen su memoria colectiva viva y, a través del canto y la música, revitalizan (kawsay) sus saberes.

Al igual que el arpa y la guitarra, el charango también adquiere protagonismo en la novela. Este instrumento es ejecutado por el indio Antolín, hermano de Marino. El indio comerciante y arriero "[e]ra alto, de nariz aguileña, de labios delgados y de pómulos brillantes que resaltaban (...). Tocaba charango, y era 'negociante arriero"' (1983, T. II, p. 15). Mientras Mariano se nutre de la naturaleza para crear sus melodías, Antolín ha heredado la vena musical de su padre y abuelo.

La presencia del arpa, la guitarra y el charango en la novela expresan, tanto en el plano real como ficcional, la capacidad creativa y musical del hombre del ande. En el personaje Mariano, se concretiza la fortaleza del indio para transformar e incorporar las melodías del arpa a su vertiente musical india. A su vez, el charango, reinterpretación transcultural de la guitarrilla renacentista española o también conocida como guitarra vieja, ${ }^{4}$ es el resultado de un proceso de sincretismo cultural, ya que sus formas organológicas, interpretativas y técnicas fueron cambiando hasta ser conquistado totalmente por el carácter melancólico, alegre y vivaz de la música india y mestiza.

El charango es la representación más concreta de la conquista cultural y musical del hombre del ande ante los elementos foráneos que llegaron con la 
conquista. Esto demuestra el carácter permeable del indio para tomar saberes de otra cultura e incorporarlos a la suya sin perder la esencia de su matriz cultural. La conquista de instrumentos musicales pertenecientes a una cultura foránea ha permitido que el pensamiento andino se unifique y revitalice para afirmar su resistencia cultural.

\section{La música como signo de identidad}

El segundo aspecto relacionado con la unificación se centra en la función de la música como signo de identidad. El personaje principal, Mariano, proviene de un pueblo frutero en el que la vida es apacible y tranquila. Allí las fiestas son el tiempo y espacio de la diversión y de la alegría; se trata de un lugar apropiado en el que los campesinos viven momentos de jolgorio y emoción, sin fuerzas que se contraponen ni conflictos; así, en armonía y bajo una lenta y calmada atmósfera, vive el comunero. En este contexto, sus costumbres, ritos y bailes se practican con total libertad, se fortalece su identidad, su relación con la naturaleza y las costumbres se van arraigando en sus prácticas culturales.

Los rituales festivos de las comunidades indias y mestizas se presentan como hechos hiperbolizados de gran relevancia y no como una acción pintoresca de los personajes. Por el contrario, estos rituales expresan un hondo significado que nos permite comprender las relaciones identitarias que se fortalecen en un espacio y tiempo. En la novela, encontraremos tres tipos de rituales celebrativos que desencadenan los hechos narrados. El primer acto festivo es el que se desarrolla en el pueblo frutero del arpista Mariano:

No habían [sic] allí verdaderos terratenientes voraces y crueles. Lenta, sin acontecimientos súbitos, la vida cursaba tranquila. Las pocas fiestas estaban previstas; y la gente se preparaba para ellas todo el año. Duraban dos o tres días; días grandes, de bailes, cantos y convites abundantes, con los mejores potajes. Los hombres y mujeres estrenaban ropa nueva en esos días; las mujeres se alhajaban y los niños contemplaban los bailes y danzas, jugaban en las huertas; algunos lloraban, perdidos en la oscuridad durante las danzas nocturnas. (1983, T. II, p. 15)

En la descripción de esta celebración, se observa cómo el pueblo se unifica y compromete con la preparación de la festividad. El trabajo colectivo alcanza su máximo esplendor: hombres, mujeres y niños se preparan y comprometen en su realización durante todo el año. Los comuneros estrenan sus mejores galas y los niños participan de la celebración con sus juegos disfrutando de los bailes y danzas. Todo el ritual se desarrolla al compás de la música y los cantos del ande que revitalizan la identidad andina.

El segundo ritual que se desarrolla en la novela es la celebración de un matrimonio. El músico Mariano asiste a estos convites para contemplar las ce- 
lebraciones y bailes de los indios. En este acto ritual, se comparten potajes propios del lugar y las mujeres visten sus mejores trajes como signo de identidad. Los matrimonios son celebraciones colectivas que la comunidad india festeja en su totalidad, tal como se puede apreciar en la siguiente escena:

Cierta vez, durante la celebración de un matrimonio, las mujeres le llevaron un plato de patachi y de algún otro potaje escogido, y no los aceptó; a pesar de que para convidarle tuvieron que caminar mucho (...). Mariano se quedó de pie (...) Y vio cómo los indios bailaban en grandes círculos; y miró a los arpistas que tocaban en una esquina del pampón. ¡Era por ellos que había baile, que los hombres y mujeres danzaban con tanta alegría! (1983, T. II, p. 13)

Los indios comparten espacios de celebración, el trabajo colectivo se concretiza en los actos de reciprocidad (ayni). Los indios celebran y danzan en comunidad; de esta forma, afianzan su identidad. En estos contextos, la danza y la música actúan como agentes revitalizantes y de unificación.

En los rituales y espacios de celebración, se redefine y nutre nuestra identidad; a través de este ejercicio de vitalidad y revitalización, se mantienen la identidad y la memoria colectiva. En esta misma línea, Laite y Long nos explica: "Así se explica por qué, en los nuevos contextos de globalización y mercantilización, la fiesta no ha desaparecido del Perú, sino que muestra una gran vitalidad y vigencia” (Cit. de Cánepa, p. 2008).

Por último, el tercer ritual festivo es la fiesta ofrecida al señor de Lambra. En los pueblos del ande se agasaja, como acto de reciprocidad, a los comerciantes $\mathrm{y}$ arrieros con quienes se ha realizado un trueque o intercambio de productos (ayni). Este hecho se narra en el siguiente pasaje:

(...) Don Aparicio la trajo desde su lejano pueblo, de vuelta de un largo viaje de negocios. Llevó a vender veinte caballos finos y cien mulas, y las cambió por reses. La conquista y rapto de Irma fueron una aventura corriente. La conoció en un paseo y jarana que el comprador de mulas organizó para agasajar a don Aparicio (...)

El paseo dedicado a don Aparicio fue muy concurrido y de los "grandes". La llegada de algún forastero importante era siempre la mejor oportunidad para realizar banquetes y fiestas que todos los vecinos principales del pueblo deseaban. (1983, T. II, p. 26)

El tema de la festividad se describe de manera hiperbolizada en Diamantes y pedernales. Los habitantes de los pueblos viven sus actos festivos y sus celebraciones con gran jolgorio, donde concurren el baile, la música y la danza. En el pasaje, observamos que se realizan actos celebrativos para corresponder ante una acción. A don Aparicio se le corresponde con reciprocidad ante la reali- 
zación de un intercambio de ganado, un trueque. De este modo, se mantiene el equilibrio y se fortalece la identidad, los usos y costumbres del pueblo se afianzan, se concretizan los principios andinos que rigen la vida del universo andino: "Ciertamente, en los Andes la fiesta (...) es un suceso que estructura y ordena la vida de sus protagonistas, un universo con significados que expresan visiones del pasado, vivencias del presente y aspiraciones ante el futuro" (Romero, 2008, p. 12) 5 .

El universo andino se organiza a partir de la reciprocidad, compromete a todos los miembros de la comunidad a actuar de manera fraterna y correspondida. Este principio no solo articula las relaciones humanas, sino que también, establece la interacción con la naturaleza, así como el lazo entre el hombre y los seres vivos. El ayni no es voluntario, por el contrario "se trata de un deber cósmico que refleja un orden universal del que el ser humano forma parte" (Estermann, 1998, p. 132). Antolín, en reciprocidad y unificación con la naturaleza, conserva y práctica los rituales de pago a la tierra, a sus apus; con ello, expresa su identidad cultural. El principio de reciprocidad se plasma en el siguiente episodio:

Escalaron juntos la cordillera. Por la región de las huertas y las faldas de las montañas que circundan la comunidad, caminaron de noche. Amaneció cuando la última abra estaba próxima. Se sentaron a descansar en la cumbre. Antolín rezó en quechua y ofreció un poco de cañazo al abra y a la pampa temible que empezaba, cerca, al pie de los nevados. (1983, T. II, pp. 17-18)

Antolín anima a Marino a viajar a los pueblos desconocidos donde los músicos, como él, son famosos y viven bien. Antolín acompaña al arpista a escalar la cordillera, hasta llegar a la cima indicándole la ruta que debe seguir para llegar a los pueblos donde residían "los todopoderosos". Antes de ver partir a Mariano, Antolín realiza el pago a las montañas, a la cordillera, a los parajes que el arpista atravesará para llegar a su destino. Según la visión andina, a todo acto le corresponde un acto complementario, que contribuye y reciproca. Esta respuesta puede que no se dé en simultáneo, pues el hombre del ande sabe que existe un equilibrio cósmico al que apela a través de actos celebrativos.

En el pasaje citado, Antolín ofrenda el cañazo a las cumbres y a las pampas bravas, dedica sus rezos en quechua a las montañas y ve partir a su hermano Mariano. Al perderlo de vista en la meseta, vuelve a realizar el pago a las montañas: "Cuando perdió de vista a su hermano, Antolín, el arriero, derramó nuevamente unas gotas de agua ardiente sobre su cumbre, y empezó a bajar la montaña, hacia su pueblo" (1983, T. II, p. 18). Antolín, quien apertura y cierra el acto ceremonial, agradece a los apus, a la pachamama y a todos los seres divi- 
nos para que le den energía y lo cuiden en su travesía. Los apus se encargarán de acompañar a Mariano y al killincho en su largo viaje.

E1 principio de la reciprocidad adquiere valor en todos los actos de la vida del hombre del ande. A través de él, se identifica la unificación de todos los elementos del cosmos. Este aspecto es analizado por Estermann (1998), quien sostiene que existen múltiples formas e interacciones de reciprocidad en diversos momentos de la vida en el mundo andino. Entre ellos, cita la "reciprocidad económica de trabajo e intercambio comercial, familiar de (com-) parentesco y ayuda mutua, ecológica de restitución recíproca a la pachamama y a los apus" (p. 134). El ayni establece esa relación cósmica entre el hombre, las divinidades y el universo andino del cual forma parte.

En Diamantes y pedernales, el runa se ve representado como un ser sometido y entregado al servicio de los mistis. Mariano e Irma sirven a don Aparicio con total fidelidad. Del mismo modo, los indios que pertenecen al ayllu de Alk'amare proyectan total obediencia. Las indias del pueblo de Lambra y el varayok indio se ven sometidos a los deseos y caprichos de don Aparicio:

El varayok' cruzó los pampones y callejuelas del barrio, en silencio, sin mirar a nadie; las jóvenes indias lo seguían sin demostrar ninguna alegría, ningún sentimiento que pudiera ser reconocido por las mujeres del barrio indio. " $¡ Q u e ́$ es pues esto? — se preguntaban ellas-. ¿Por qué no cantan? ¿A qué vienen con sus trajes de fiesta? ¡No es tampoco para un muerto!"

En el barrio central, las señoras y señoritas, los jóvenes y caballeros lo comprendieron todo.

— ¿Qué escándalo! — dijo uno- ¡El varayok' a las órdenes de don Aparicio para una alcahuetería! (1983, T. II, p. 25)

Los indios estaban al servicio del misti, estos proyectaban total obediencia ante los pedidos del señor de Lambra. Sin embargo, a este pasaje narrado le antecede una descripción de los usos y costumbres de los indios del pueblo de Lambra. El varayok' porta su "vara gruesa de chonta", simbólicamente decorado con elementos andinos y mestizos. Del mismo modo, las mujeres indias de Lambra se presentan con los trajes típicos de su comunidad. Estos implementos permiten que la gente del pueblo de K'allak'ata las identifique como indias del pueblo de Lambra:

Cada mujer llevaba en las manos un ramo de achank'arayes blancos y violáceos y sobre la cinta del sombrero, como anchos adornos, flores de phalcha azules y grises. El viejo alcalde indio empuñaba una vara gruesa de chonta, ajustada con anillos de plata: insignia de su autoridad. 
En el extremo alto de la vara, el de mayor diámetro, estaba cubierto de plata que tenía en su centro una cruz.

Sobre el madero negro de la vara del pueblo lucían las franjas de metal. Cada anillo era un pallay, una cinta labrada: pájaros, flores, venados y caballos, dibujados a cincel, y en el borde una línea, a manera de marco (...) Por el vestido de bayeta azul oscuro y la montera con franjas doradas, en forma de cruz sobre la copa, reconocieron que era gente de Lambra. (1983, T. II, p. 24)

La representación de un pueblo subyugado ante el poder del gran señor de Lambra se convierte, ante la mirada de un lector atento, en un acto de resistencia cultural, de defensa de los usos y costumbres de los indios del pueblo de Lambra. El vestir de las indias muestra el tejido de animales que representa la cosmovisión andina. De la misma manera, en la vara de chonta del varayok, resalta la descripción de cada elemento de la flora y la fauna: seres de quienes emana fuerza revitalizante que se proyecta sobre los indios, quienes muestran una defensa pasiva como acto de resistencia de su cultura. Al respecto, Cornejo Polar sostiene: "En contraste con su pasividad social, con la sumisión que los encadena, los indios de Diamantes y pedernales demuestran una vigorosa unificación: silenciosamente, pero con firmeza reiteran los valores de su cultura y lo demuestran con seguro orgullo" (1997, p. 12).

En efecto, los productos culturales andinos, como el vestido, y los instrumentos rituales, como la vara de chonta, las flores de achank'arayes y la montera, articulan la identidad india con la cosmovisión andina. En tal sentido, la música en Diamantes y pedernales adquiere una capacidad articuladora e integradora que posibilita la defensa de la cultura andina.

\section{La indumentaria como elemento cultural de unificación}

En Diamantes y pedernales, como en todo el proyecto narrativo de Arguedas, apreciamos un número significativo de manifestaciones culturales que están relacionadas con la cosmovisión andina y que consolidan la identidad de los integrantes de la comunidad o del ayllu. Estos elementos se hallan simbólicamente representados en diversos objetos que forman parte de la vida del indio y de la comunidad. Así, por ejemplo, el chumpi, el tejido y los potajes se convierten en elementos vivificadores y unificadores de la cultura andina.

El siguiente esquema plantea un acercamiento a los elementos culturales de unificación en la novela de Arguedas: 


\section{Figura 2: Clasificación de los elementos culturales en Diamantes y pedernales}

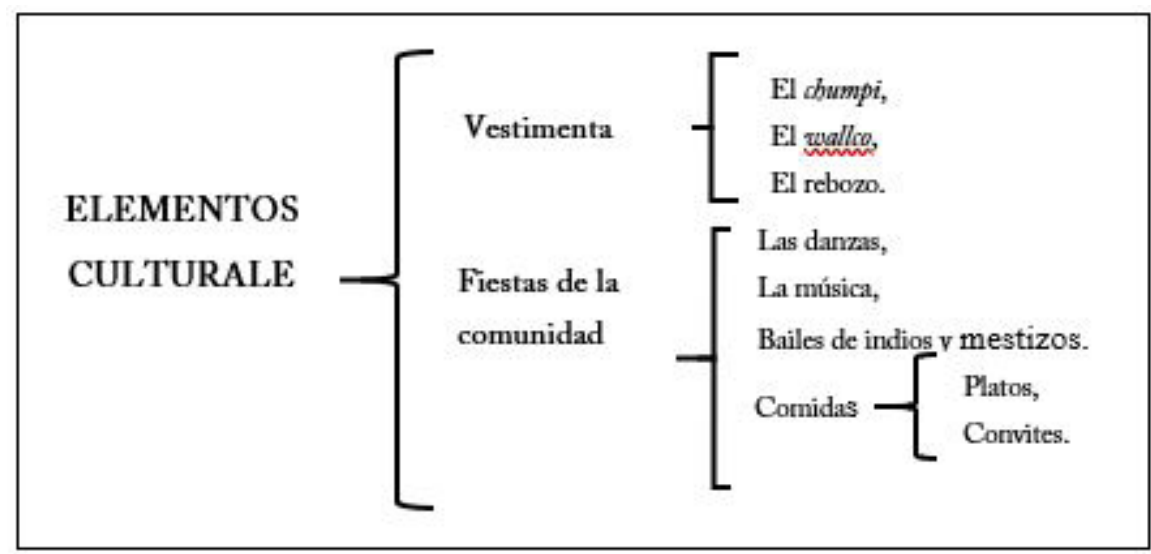

Fuente: Elaboración propia

En diversos episodios de la trama narrativa de Diamantes y pedernales, se describen objetos de la indumentaria de los personajes que se asocian con espacios y tiempos de fiestas, rituales, ceremonias, etc., que se viven en la comunidad. En ese sentido, la vestimenta es un elemento cultural que unifica a los miembros de la comunidad o ayllu. En la indumentaria, resalta el chumpi de los varones y el rebozo de las mujeres, así como el wallco, que aparece en el ritual de la despedida.

\subsection{El chumpi}

En la novela, esta parte de la indumentaria adquiere relieve cuando el Upa Mariano llama la atención de las mujeres al observar el bello chumpi que el arpista exhibe en las fiestas de la comunidad:

Sólo él usaba esa clase de fajas. Desde su lejano pueblo, algún indio vendedor de fruta le traía, de tiempo en tiempo, un cinturón nuevo y llamativo que sus hermanas le enviaban como recuerdo. En el fondo rojo o azul de tejido, las figuras reciamente compuestas, de toros, patos o caballos, resaltaban como si estuvieran vivos. (1983, T. II, p. 12)

El tejido se asocia con el telar, con el manto, con un campo semántico de significados referidos a la vida, a la historia, al pasado, a la memoria, con un sentido profético y trascendente. Los seres que decoran bellamente la faja del Upa Mariano son seres que denotan vitalidad. Así, el toro, los patos y los caballos resaltan en el tejido porque tienen vida. Esto llama la atención de las mujeres de la comunidad, quienes observan con curiosidad a los seres del kay pacha. 
Desde otra mirada, el chumpi usado por el músico mantiene el equilibrio del upa Mariano, ya que, por estar ubicado en la cintura, sirve para contener la energía y otorgar fuerza y equilibrio al indio.

\subsection{Rebozos de castilla}

El rebozo o pañolón es parte del vestuario de las mujeres de la comunidad. Estas utilizaban este complemento para asistir a las ceremonias religiosas. En la novela, se usa el rebozo para entonar el harawi de la despedida a Antolín. También, se usa cuando se entona el aya-harawi en los funerales indios del Upa Mariano. Otro momento en que las mujeres lucen sus trajes típicos es en la celebración de los matrimonios: "fueron tan hermosamente vestidas, con sus largos rebozos de castilla cubriéndoles la espalda (...) Tuvieron que cruzar media calle con los platos escondidos bajo el rebozo" (1983, T. II, p. 13). Este accesorio de la vestimenta permite identificar el lugar de origen y las características de los trajes típicos. Así, se fortalece la identidad de la mujer del ande, lo que afirma su lazo con la comunidad y con los usos y costumbres del pueblo.

\subsection{E1 wallco}

El wallco es un collar de frutas y flores que se coloca a los hombres a modo de banda presidencial. En la novela, en la escena en que se despide a Antolín, las mujeres solteras y bellas le colocan el wallco como símbolo de buen viaje, suerte y buenos deseos para el arriero. Por otro lado, el wallco, también, simboliza al amor, la entrega y una forma de reciprocidad hacia el indio, en quien el pueblo ha depositado todas sus esperanzas y fe en el cumplimiento de su tarea.

\subsection{Las fiestas de la comunidad}

Se constituyen en espacios de diversión y jolgorio que comparte toda la comunidad. En Diamantes y pedernales, se mencionan fiestas y rituales celebrativos que tienen lugar en las comunidades indias y mestizas. En estas celebraciones, se comparten diversos platos típicos y potajes entre los miembros de la comunidad. Entre los platos típicos, se menciona el patachi, que se sirve en el ritual del matrimonio indio. Estas celebraciones son acompañadas de danzas como los carnavales y marineras.

La presencia de estos elementos identitarios en la novela se relaciona con la cultura y la cosmovisión de la comunidad andina. Los rituales, las celebraciones de las fiestas y el afianzamiento de los usos y costumbres fortalecen los lazos de unificación en el seno de la comunidad. De esta manera, quienes asisten a estas prácticas y son partícipes de ellas, sobre todo niños y jóvenes, escuchan, aprenden y nutren su memoria colectiva. 


\section{Conclusión}

En el mundo representado de Diamantes y pedernales de Arguedas, la música cumple el rol de agente unificador y revitalizador de la cultura andina; lo que se articula con los principios que explican el funcionamiento de su cosmovisión. En ese sentido, la música, el canto y la danza se conectan con la totalidad de los seres que conforman el universo andino de acuerdo con la noción de relacionalidad. En la novela, la música procede de fuentes de emisión que se refieren a la intervención de los personajes, como Irma y Mariano, y al empleo de instrumentos musicales, como el arpa, el charango y la guitarra; de igual modo, se expresa a través de los géneros musicales que se cantan en diferentes rituales y prácticas culturales de la comunidad. De esta manera, la música se liga a la unificación e integración en el contexto del mundo andino novelado en Diamantes y pedernales.

En la novela arguediana, igualmente, la vestimenta se convierte en un signo de la identidad india. Los objetos o prendas que forman parte de la indumentaria de los personajes se asocian con celebraciones y rituales propios de la comunidad en los cuales se impregnan de un determinado significado. En tal sentido, la música con su función de revitalización y la indumentaria fortalecen los valores de la comunidad india en el universo narrativo de Diamantes y pedernales.

\section{Notas}

1 Las referencias citadas de Diamantes y pedernales se toman del tomo II de las Obras completas de Arguedas editadas por la Editorial Horizonte (1983).

2 Un estudio más amplio sobre el arpa en la región andina es desarrollado en la Revista Andina de Musicología, n’ $12-13$ (2012). Específicamente, puede revisarse el artículo El arpa en la cosmovisión andina de Claude Ferrier (pp. 125-150).

3 El carácter femenino del arpa, según Ferrier (2012), es asumido por los arpistas del Valle del Mantaro.

4 En Charango, Chalena Vásquez (2017) realiza un interesante estudio sobre dicho instrumento musical (Serie Música Peruana. Vol. 1, Pontificia Universidad Católica del Perú).

5 Ver Fiesta en los Andes. Ritos, música y danzas del Perú (2008) de Raúl Romero (Ed.). Lima: Fondo Editorial de la Pontificia Universidad Católica del Perú.

\section{Referencias bibliográficas}

Arguedas, J. M. (2012). Obra antropológica. 7 t. Lima: Horizonte.

Arguedas, J.M. (1983). Obras completas. 5 t. Lima: Horizonte.

Cánepa, G. (2008). Fiestas en los Andes. Ritos, Música y Danzas del Perú. Lima: Fondo Editorial de la Pontificia Universidad Católica del Perú. 
Cornejo Polar, A. (1997). Los universos narrativos de José María Arguedas. 2 ed. Lima: Horizonte.

Ferrier, C. (2012). "El arpa en la cosmovisión andina”. Revista Andina de Musicología, (12-13). Disponible en: https://www.academia.edu/6695764/El_arpa_en_la_ cosmovis\%C3\%B3n. Fecha de consulta: 06-07-2019.

D'Harcourt, R. y M. (1990 [1925]). La música de los Incas y sus supervivencias. Lima: OXI.

Estermann, J. (1998). Filosofía Andina. Estudio intercultural de la sabiduría autóctona andina. Cusco: Ediciones Abya Yala.

García, F. y Roca, P. (2004). Pachakuteq. Una aproximación a la cosmovisión andina. Lima: Fondo Editorial del Pedagógico San Marcos.

Huamán, C. (2015). Urpischallay. Transfiguraciones poéticas, memoria y cultura andina en el wayno. Lima: Altazor.

Lienhard, M. (1992) La voz y su huella. 2a ed. Lima: Horizonte.

Mamani, M. (2011). José María Arguedas. Urpi, fieru, quri, sonqoyky. Estudio sobre la poesia de Arguedas. Lima: Petroperú.

Mendívil, J. (2018) Cuentos fabulosos: La invención de la música incaica y el nacimiento de la música andina como objeto de estudio etnomusicológico. Lima: Pontificia Universidad Católica del Perú e Instituto Francés de Estudios Andinos.

- (2002) La construcción de la historia: el charango en la memoria colectiva mestiza ayacuchana. Revista musical chilena, 56 (198), 63-78

Romero Cevallos, R. (2017) Todas las músicas. Diversidad sonora y cultural en el Perú. Lima: Instituto de Etnomusicología de la Pontificia Universidad Católica del Perú.

- (Ed.) (2008) Fiesta en los Andes. Ritos, música y danzas del Perú. Lima: Fondo Editorial de la Pontificia Universidad Católica del Perú.

Vásquez, C. (2013). Luz y sonido en la obra de José María Arguedas. Una propuesta de musicologia andina. Disponible en: http://www.chalenavasquez.com/almacen/ponencias/fragmentos-luzysonidoenJMaponencia.pdf. Fecha de consulta: 18-06-2018.

- (2008). Historia de la música en el Perú. Disponible en: http://www.chalenavasquez.com/almacen/libros/aquellamamossonido-musica.pdf Fecha de consulta: $18-02-2017$.

Wolff Unruh, V. (1983). El mundo disputado al nivel del lenguaje. Iberoamericana, 49(122), 193-202 